Short Communication

Human and Medical Genetics

\title{
Prevalence of the most common pathogenic variants in three genes for inborn errors of metabolism associated with sudden unexpected death in infancy: a population-based study in south Brazil
}

Dévora N. Randon ${ }^{1,2}$, Fernanda Sperb-Ludwig ${ }^{1,2}$ (iD, Fernanda S. L. Vianna ${ }^{1,3,8,9}$, Ana P. P. Becker ${ }^{4}$, Carmen R. Vargas ${ }^{5}$, Angela Sitta ${ }^{6}$, Alexia N. Sant'Ana ${ }^{7}$, Ida V. D. Schwartz ${ }^{1,2,6,8}$ iD and Fernanda H. de Bitencourt ${ }^{9}$ iD

${ }^{1}$ Universidade Federal do Rio Grande do Sul (UFRGS), Programa de Pós-Graduação em Genética e Biologia Molecular, Porto Alegre, RS, Brazil.

${ }^{2}$ Hospital de Clínicas de Porto Alegre (HCPA), Centro de Pesquisa Experimental, Basic Research and Advanced Investigations in Neurosciences (BRAIN), Porto Alegre, RS, Brazil.

${ }^{3}$ Hospital de Clínicas de Porto Alegre (HCPA), Centro de Pesquisa Experimental, Laboratório de Medicina Genômica, Porto Alegre, RS, Brazil.

${ }^{4}$ Universidade Federal do Rio Grande do Sul (UFRGS), Faculdade de Medicina, Porto Alegre, RS, Brazil.

${ }^{5}$ Universidade Federal do Rio Grande do Sul (UFRGS), Faculdade de Farmácia, Porto Alegre, RS, Brazil.

${ }^{6}$ Hospital de Clínicas de Porto Alegre (HCPA), Serviço de Genética Médica, Porto Alegre, RS, Brazil.

${ }^{7}$ Universidade Federal do Rio Grande do Sul (UFRGS), Instituto de Biociências, Porto Alegre, RS, Brazil.

${ }^{8}$ Universidade Federal do Rio Grande do Sul (UFRGS), Departamento de Genética, Porto Alegre, RS, Brazil.

${ }^{9}$ Hospital de Clínicas de Porto Alegre (HCPA), Instituto Nacional de Genética Médica Populacional (INAGEMP), Porto Alegre, RS, Brazil.

\begin{abstract}
Citrullinemia type 1 (CTLNI), long-chain 3-hydroxyacyl-CoA dehydrogenase deficiency (LCHADD), and mut ${ }^{0}$ methylmalonic acidemia (mut ${ }^{0} \mathrm{MMA}$ ) are inborn errors of metabolism (IEMs) associated with sudden unexpected death in infancy (SUDI). Its most common pathogenic variants are: c.1168G>A (CTLNI, ASS1 gene), c.1528G>C (LCHADD, HADHA gene), c.655A>T and c.1106G>A (mut ${ }^{0}$ MMA, MUT gene). Considering the absence of estimates regarding the incidence of these diseases in Brazil, this study sought to investigate the prevalence of its main pathogenic variants in a healthy population in the southern region of the country. A total of 1,000 healthy subjects from Rio Grande do Sul were included. Genotyping was performed by real-time PCR. Individuals found to be heterozygous for c. $1528 \mathrm{G}>\mathrm{C}$ underwent further acylcarnitine profile analysis by tandem mass spectrophotometry. Allele and genotype frequencies were calculated considering Hardy-Weinberg equilibrium. The c.1528G $>C$ variant was detected in heterozygosity in two subjects (carrier frequency $=1: 500$; allele frequency $=0.001$; minimum prevalence of LCHADD $=1: 1,000,000$ ), whose acylcarnitine profiles were normal. Variants c.1168G >A, c.655A $>T$, and c.1106G>A were not identified. These results denote the rarity of these IEMs in Southern Brazil, highlighting the need to expand the investigation of IEMs in relation to infant morbidity and mortality within the country.
\end{abstract}

Keywords: Citrullinemia type I, long-chain 3-hydroxyacyl-CoA dehydrogenase deficiency, mut0 methylmalonic acidemia, pathogenic variants, prevalence.

Received: October 03, 2019; Accepted: June 17, 2020.

Sudden unexpected death in infancy (SUDI) refers to the death of a child that occurs suddenly and unexpectedly during the first year of life, and represents one of the leading causes of post-neonatal death (Krous et al., 2004). Inborn errors of metabolism (IEMs) are estimated to account for $0.9 \%$ to $6 \%$ of such events (Boles et al., 1998; Chace et al., 2001;

Send correspondence to Ida V. D. Schwartz. Hospital de Clínicas de Porto Alegre, Serviço de Genética Médica. Rua Ramiro Barcelos, 2350, 90035-003, Porto Alegre, RS, Brazil. E-mail: idadschwartz@gmail.com. van Rijt et al., 2016). Among the IEMs known to be associated with SUDI, citrullinemia type 1 (CTLNI; MIM \#215700), long-chain 3-hydroxyacyl-CoA dehydrogenase deficiency (LCHADD; MIM \#609016) and mut ${ }^{0}$ methylmalonic acidemia ( mut $^{0}$ MMA; \#MIM 25100), among other autosomal recessive IEMs, are treatable and identifiable by neonatal screening (van Rijt et al., 2016).

CTLNI is a urea cycle disorder caused by deficiency of the enzyme argininosuccinate synthetase (ASS, EC 6.3.4.5) due to pathogenic variants in the ASS1 gene (Beaudet et al., 
1986). Among these, c.1168G $>$ A (p.Gly390Arg) in exon 15 accounts for up to $62 \%$ of alleles in European patients diagnosed with the disorder (Diez-Fernandez et al., 2017). LCHADD, a disorder of fatty-acid beta-oxidation, is caused by pathogenic variants in the $H A D H A$ gene, which encodes the alpha subunit of the mitochondrial trifunctional protein (MTP; EC 1.1.1.211) (IJlst et al., 1994). Variant c.1528G $>$ C (p.Glu510Gln) in exon 15 was observed in 87-91\% of European patients with clinically overt disease (Nedoszytko et al., 2017). Certain variants in the MUT gene, which codes for the enzyme methylmalonyl-CoA mutase (MUT; EC 5.4.99.2), are responsible for mut ${ }^{0}$ MMA, a disorder of propionate catabolism (Ledley et al., 1988). The most frequent implicated variants are c.655A $>\mathrm{T}$ (p.Asn219Tyr), in exon 3, and c.1106G $>$ A (p.Arg369His), in exon 6, representing approximately $25 \%$ (Acquaviva et al., 2005) and 10\% (Forny et al., 2016) of alleles in European patients, respectively.

Considering that the aforementioned IEMs are not included in the Brazilian nationwide neonatal screening program and that there are no estimates regarding their incidence in the country, we aimed at investigating the presence of the most prevalent pathogenic variants associated with these conditions in a healthy population in the state of Rio Grande do Sul, southern Brazil.

This was an observational, cross-sectional study with a convenience sampling strategy.

The sample size was estimated at 980 individuals. Calculation was performed in WINPEPI (PEPI-for-Windows, version 11.65), based on the known proportion of heterozygotes for variant c. $1528 \mathrm{G}>\mathrm{C}(H A D H A)$ in European populations (den Boer et al., 2000; Joost et al., 2012), an error rate of $0.3 \%$, statistical power of $80 \%$, alpha $=0.05$, and $95 \%$ confidence interval $(95 \% \mathrm{CI})$.

Participants were recruited from the blood bank at Hospital de Clínicas de Porto Alegre, Rio Grande do Sul, Brazil, a tertiary teaching hospital affiliated with Universidade Federal do Rio Grande do Sul, between August 2017 and March 2019. Each participant completed a form designed to collect data on date and place of birth and ancestry (European or non-European).

From each participant, a $5 \mathrm{~mL}$ sample of peripheral blood was collected into an EDTA-containing tube and stored at $-20^{\circ} \mathrm{C}$. Genomic DNA was extracted with the commercially available Easy-DNA Kit (Invitrogen, Carlsbad, CA, USA), following the manufacturer-provided protocol.

Genomic DNA was analyzed by real-time polymerase chain reaction (RT-PCR) with TaqMan genotyping (Thermo Fisher) in StepOne and QuantStudio 3 systems (Thermo Fisher), performed in accordance with the manufacturer's instructions. Custom TaqMan genotyping assays were ordered from Applied Biosystems (Foster City, CA, USA), based on the reference sequences NG_011542.1 (ASS1), NG_007121.1 (HADHA), and NG_007100.1 (MUT).

Individuals heterozygous for the c. $1528 \mathrm{G}>\mathrm{C}$ variant $(H A D H A)$ also underwent acylcarnitine profile analysis by tandem mass spectrometry (MS/MS) using peripheral blood on filter paper samples, based on the protocol established by Rashed et al. (1997).

Statistical analyses were performed in SPSS Version 22.0 (IBM Corp., Armonk, NY, USA). The carrier frequency was obtained by calculating the ratio of heterozygous individuals to the total number of individuals analyzed, and reported with a $95 \% \mathrm{CI}$. Gene and genotype frequencies were calculated assuming Hardy-Weinberg equilibrium in the population.

The study protocol was approved by the local Research Ethics Committee, in accordance with Brazilian regulations for human subject research (under reference number 17-0249) and all participants provided written informed consent. Individuals who were found to be heterozygous were convoked for genetic counseling purposes.

The study sample consisted of 1,000 voluntary blood donors, with a mean age of $36.6 \pm 12.1$ years (range $19-69$ years) (Table 1).

Variants c. $1168 \mathrm{G}>\mathrm{A} \quad(A S S 1), \quad$ c. $655 \mathrm{~A}>\mathrm{T}$ and c. $1106 \mathrm{~T}>\mathrm{A}(M U T)$ were not identified in the analyzed sample. Two subjects $(0.2 \%)$ were found to be heterozygous for the c. $1528 \mathrm{G}>\mathrm{C}(H A D H A)$ variant (Table 2$)$, which corresponds to a carrier frequency of $1: 500 \quad(95 \% \mathrm{CI}$ $0.02 \%-0.72 \%$ ). The resulting allele frequency for c. $1528 \mathrm{G}$ and c. $1528 \mathrm{C}$ were 0.9980 (95\%CI 0.9949-0.9995) and 0.001 (95\%CI 0.0001-0.0036), respectively. The estimated minimum prevalence for LCHADD as a consequence of the c. $1528 \mathrm{C}$ allele in Rio Grande do Sul was 1:1,000,000. The acylcarnitine profiles of both individuals heterozygous for c. $1528 \mathrm{G}>\mathrm{C}$ were normal.

The Brazilian population is one of the most ethnically heterogeneous of the world, as the result of five centuries of miscegenation among indigenous, European, and African

Table 1 - Characteristics of the study sample $(\mathrm{N}=1,000)$.

\begin{tabular}{lc}
\hline Variable & $\mathrm{N}(\%)$ \\
\hline Sex & \\
Male & $504(50.4 \%)$ \\
Female & $496(49.6 \%)$ \\
Birthplace & \\
Rio Grande do Sul & $922(92.2 \%)$ \\
Porto Alegre & $470(47.0 \%)$ \\
Other municipalities & $452(45.2 \%)$ \\
Other states & $75(7.5 \%)$ \\
Other countries & $3(0.3 \%)$ \\
Ancestry & \\
European & $639(63.9 \%)$ \\
German & $272(27.2 \%)$ \\
Italian & $202(20.2 \%)$ \\
Portuguese & $110(11.0 \%)$ \\
Other European & $55(5.5 \%)$ \\
No European ancestry & $252(25.2 \%)$ \\
Unknown & $109(10.9 \%)$ \\
\hline
\end{tabular}


Table 2 - Characteristics of individuals heterozygous for variant c. $1528 \mathrm{G}>\mathrm{C}(H A D H A)$.

\begin{tabular}{lcccc}
\hline Subject & Sex & Age (years) & Birthplace & European ancestry \\
\hline 1 & Female & 52 & Porto Alegre & Yes \\
2 & Female & 29 & Porto Alegre & No \\
\hline
\end{tabular}

populations. In the southern region, European ancestry predominates (Parra et al., 2003; Moura et al., 2015) as our data corroborate. This predominance of European ancestry might suggest that the prevalence of the variants of interest in the population of Rio Grande do Sul would be similar to that reported in European countries.

The absence of the c.1168A allele (ASS1) could be indicating its rarity in the region, in agreement with the information available in the Exome Aggregation Consortium (ExAC) and in the Genome Aggregation Database (gnomAD), which show a frequency of $\sim 0.0003$, both for European and global populations. However, these databases do not include information about Brazilian individuals. The Brazilian Online Archive of Mutations (ABraOM), which catalogs exon variants from 609 healthy elderly from the city of São Paulo, in Southeast Brazil, shows a similar frequency, of 0.0016 (Naslavsky et al., 2017).

The prevalence of c. $1168 \mathrm{~A}$ was previously described for USA and Argentine populations (Table 3). In the USA, Bardos et al. (2019) determined a carrier frequency of 1:383 and a prevalence of $1: 575,000$, contradicting the estimated overall incidence of CTLNI $(\sim 1: 250,000)$ (Summar et al., 2013). The authors have suggested that this discrepancy could be explained by a possible overestimation of CTLNI prevalence reported in the literature, or by an overestimate of the frequency of the pathogenic variants included in their assay (Bardos et al., 2019). In comparison, in the city of Villa Mercedes, Argentina, Laróvere et al. (2012) reported a carrier frequency of $1: 25$ and a prevalence of $1: 2,427$. Additionally, the authors determined a CTLNI occurrence of $57 \%$ for the offspring of couples consisting of two heterozygous individuals, a much higher frequency than expected for autosomal recessive disorders, which suggests a preferential transmission of the c.1168A allele. This phenomenon was previously proposed by Kleijer et al. (2006), based on the high rate of affected fetuses (39.5\%), diagnosed from a total of 91 pregnancies at 1 in 4 risk. They proposed that the preferential transmission of any citrullinemic allele might arise from a protective role of ASS deficiency in haploid mutant sperm cells against the possibly detrimental or apoptotic effect of nitric oxide, produced normally from arginine by nitric oxide sintetase. The possibility of a preferential transmission highlights the relevance of this pathogenic variant in relation to early diagnosis and genetic counseling for populations at risk.

The allele frequency estimated in this study for the variant c. $1528 \mathrm{G}>\mathrm{C}(H A D H A)$ is in agreement with ExAC and gnomAD data, which show a frequency of 0.0012 for the global population and 0.0016 for Europe (non-Finnish).

Table 3 - Carrier frequency of the c.1168G $>\mathrm{A}(A S S 1)$ and c.1528G $>\mathrm{C}(H A D H A)$ variants in different populations.

\begin{tabular}{|c|c|c|c|c|}
\hline Variant & Population & $\begin{array}{c}\text { Number of heterozygotes/Number of } \\
\text { analyzed individuals }\end{array}$ & Carrier frequency & References \\
\hline \multirow[t]{4}{*}{ c. $1168 \mathrm{G}>\mathrm{A}$} & Argentina & $7 / 172$ & $1: 25$ & Laróvere et al., 2012 \\
\hline & United States & $29 / 11132$ & $1: 383$ & Bardos et al., 2019 \\
\hline & Brazil (São Paulo) & $2 / 609$ & $1: 305$ & Naslavsky et al., 2017 \\
\hline & Brazil (Rio Grande do Sul) & $0 / 1000$ & 0 & This study \\
\hline \multirow[t]{16}{*}{ c. $1528 \mathrm{G}>\mathrm{C}$} & China & $0 / 1200$ & 0 & Zhu et al., 2005 \\
\hline & Estonia & $6 / 1040$ & $1: 173$ & Joost et al., 2012 \\
\hline & Finland & $5 / 1200$ & $1: 240$ & Tyni and Pihko, 1999 \\
\hline & Finland & $9 / 1637$ & $1: 181$ & Pastinen et al., 2001 \\
\hline & Finland (North) & $1 / 365$ & $1: 365$ & Pastinen et al., 2001 \\
\hline & Finland (South) & $3 / 492$ & $1: 164$ & Pastinen et al., 2001 \\
\hline & Finland (East) & $2 / 385$ & $1: 193$ & Pastinen et al., 2001 \\
\hline & Finland (West) & $3 / 392$ & $1: 132$ & Pastinen et al., 2001 \\
\hline & Netherlands & $3 / 2047$ & $1: 680$ & den Boer et al., 2000 \\
\hline & Poland (children) & $22 / 4137$ & $1: 189$ & Piekutowska-Abramczuk et al., 2010 \\
\hline & Poland (adults) & $36 / 5877$ & $1: 163$ & Nedoszytko et al., 2017 \\
\hline & $\begin{array}{l}\text { Poland (Pomerania, chil- } \\
\text { dren) }\end{array}$ & $41 / 2976$ & $1: 73$ & Piekutowska-Abramczuk et al., 2010 \\
\hline & Poland (Pomerania, adults) & $4 / 413$ & $1: 103$ & Nedoszytko et al., 2017 \\
\hline & Poland (Kashubia, adults) & $18 / 1023$ & $1: 57$ & Nedoszytko et al., 2017 \\
\hline & Brazil (São Paulo) & $2 / 609$ & $1: 305$ & Naslavsky et al., 2017 \\
\hline & Brazil (Rio Grande do Sul) & $2 / 1000$ & $1: 500$ & This study \\
\hline
\end{tabular}


Moreover, in São Paulo, the frequency is also 0.0016 (Naslavsky et al., 2017). The prevalence of this allele has been described in several populations (Table 3). We found a carrier frequency of 1:500, which exceeds the estimated frequency for the Netherlands (1:680) (den Boer et al., 2000), but is lower than reported for other European populations. The highest frequency was observed in northern Poland, with a probable founder effect in the population of Kashubia (Piekutowska-Abramczuk et al., 2010; Nedoszytko et al., 2017). In comparison, the allele was absent in all 1,200 individuals analyzed in a study in Beijing (Zhu et al., 2005). Based on the frequency of $c .1528 \mathrm{G}>C$, the birth prevalence of LCHADD is predicted to be 1:118,336 in Poland (Piekutowska-Abramczuk et al., 2010) and 1:91,700 in Estonia (Joost et al., 2012). Our findings suggest that the minimum prevalence of LCHADD in Rio Grande do Sul would be $1: 1,000,000$. According to data from neonatal MS/MS screening programs, the prevalence of this condition ranges from 1:1,148,000 in Korea to 1:840,000 in Japan (Shibata et al., 2018). It should be noted that MS/MS cannot distinguish between general mitochondrial trifunctional protein deficiency (MIM \#609015) and LCHADD.

The c.655A $>\mathrm{T}$ variant (MUT) presents an allele frequency of $\sim 0.00005$ in the global population, according to ExAC and gnomAD data, being found only in non-Finnish European populations and Ashkenazi Jews. Likewise, the overall frequency of $\mathrm{c} .1106 \mathrm{G}>\mathrm{A}(M U T)$ is reported as $\sim 0.00004$ in ExAC and $\sim 0.00006$ in gnomAD. In non-Finnish European populations, it is $\sim 0.00004$ in ExAC and $\sim 0.00007$ in gnomAD. Both variants are absent from the ABraOM database (Naslavsky et al., 2017). According to USA neonatal screening data, the prevalence of ut $^{0} \mathrm{MMA}$ is $\sim 1: 100,000$ (Feuchtbaum et al., 2012). To the best of our knowledge, there are as yet no other estimates for the frequency of these variants in healthy populations.

This was the first study to evaluate the prevalence of the most frequent pathogenic variants in the genes implicated in CTLNI, LCHADD, and mut ${ }^{0}$ MMA - three inborn errors of metabolism associated with SUDI - in a Brazilian healthy population. The low estimated prevalence of the variants is thought to denote the rarity of these disorders in Rio Grande do Sul. However, one must take into account the limitations arising from the size of the analyzed cohort, since it does not allow for the detection of low frequency variants. Another fact to consider is related to the allele heterogeneity associated with $A S S 1, H A D H A$, and $M U T$ genes. Despite the preponderance of European ancestry in southern Brazil, other pathogenic variants, which cannot be identified through the genotyping method used in the present study, may occur with a frequency higher than that established for other geographical areas currently covered in the literature. The findings of this study are particularly relevant in the context of early diagnosis and genetic counseling, and underscore the need to expand IEMs investigation in relation to infant morbidity and mortality within the territory.

\section{Acknowledgments}

The authors would like to thank the staff at the Blood Bank of the Hospital de Clínicas de Porto Alegre, especially Dr. Léo Sekine, head of the Hemotherapy Service. We are grateful to Bruna Bento, Guilherme M Pagel, Júlia L Deimling, Luiz F Portela, Marco AB Kalil, Mariana L dos Santos, Mariana Scortegagna and Vaneisse CL Monteiro, who contributed to the sample and data collection. This study was financed in part by the Coordenação de Aperfeiçoamento de Pessoal de Nível Superior - Brasil (CAPES) - Finance Code 001; Fundo de Incentivo à Pesquisa e Eventos - Hospital de Clínicas de Porto Alegre (FIPE/HCPA); Post Graduate Program in Genetics and Molecular Biology, Universidade Federal do Rio Grande do Sul (PPGBM-UFRGS); and Fundação de Amparo à Pesquisa do Estado do Rio Grande do Sul (FAPERGS/MS/CNPQ/SESRS call for papers PPSUS 03/2017).

\section{Conflict of Interest}

The authors report no conflicts of interest.

\section{Author Contributions}

DNR conceived the study design, participated in the sample and data collection, conducted the experiments, analyzed the data, and wrote the manuscript; FS-L conceived the study design and analyzed the data; FSLV conceived the study design; APPB participated in the sample and data collection; CRV participated in the sample processing and analyzed the data; AS participated in the sample processing and analyzed the data; ANS participated in the data collection and sample collection and processing; IVDS conceived and designed the study, analyzed the data, and wrote the manuscript; FHB conceived the study design, participated in the data collection, and analyzed the data. All authors read and approved the final version.

\section{References}

Acquaviva C, Benoist JF, Pereira S, Callebaut I, Koskas T, Porquet D and Elion J (2005) Molecular basis of methylmalonyl-CoA mutase apoenzyme defect in 40 European patients affected by mut $^{\circ}$ and mut- forms of methylmalonic acidemia: Identification of 29 novel mutations in the MUT gene. Hum Mutat 25:167-176.

Bardos J, Terhaar C, Echeverri N and Longman RE (2019) Carrier rate of citrullinemia, type I in individual ethnic groups using an expanded carrier test. W J Gynecol Women's Health 2:1-2.

Beaudet AL, O'Brien WE, Bock HG, Freytag SO and Su TS (1986) The human argininosuccinate synthetase locus and citrullinemia. Adv Hum Genet 15:161-196, 291-292.

Boles RG, Buck EA, Blitzer MG, Platt MS, Cowan TM, Martin SK, Yoon H, Madsen JA, Reyes-Mugica M and Rinaldo P (1998) Retrospective biochemical screening of fatty acid oxidation disorders in postmortem livers of 418 cases of sudden death in the first year of life. J Pediatr 132:924-933.

Chace DH, DiPerna JC, Mitchell BL, Sgroi B, Hofman LF and Naylor EW (2001) Electrospray tandem mass spectrometry for analysis of acylcarnitines in dried postmortem blood spec- 
imens collected at autopsy from infants with unexplained cause of death. Clin Chem 47:1166-1182.

den Boer ME, Ijlst L, Wijburg FA, Oostheim W, van Werkhoven MA, van Pampus MG, Heymans HS and Wanders RJ (2000) Heterozygosity for the common LCHAD mutation $(1528 \mathrm{G}>\mathrm{C})$ is not a major cause of HELLP syndrome and the prevalence of the mutation in the dutch population is low. Pediatr Res 48:151-154.

Diez-Fernandez C, Rüfenacht V and Häberle J (2017) Mutations in the human Argininosuccinate Synthetase (ASS1) gene, impact on patients, common changes, and structural considerations. Hum Mutat 38:471-484.

Feuchtbaum L, Carter J, Dowray S, Currier RJ and Lorey F (2012) Birth prevalence of disorders detectable through newborn screening by race / ethnicity. Genet Med 14:937-945.

Forny P, Schnellmann AS, Buerer C, Lutz S, Fowler B, Froese DS and Baumgartner MR (2016) Molecular genetic characterization of 151 mut -type methylmalonic aciduria patients and identification of 41 novel mutations in MUT. Hum Mutat 37:745-754.

IJlst L, Wanders RJ, Ushikubo S, Kamijo T and Hashimoto T (1994) Molecular basis of long-chain 3-hydroxyacyl-CoA dehydrogenase deficiency: Identification of the major disease-causing mutation in the $\alpha$-subunit of the mitochondrial trifunctional protein. Biochim Biophys Acta 1215:347-350.

Joost K, Ounap K, Zordania R, Uudelepp ML, Olsen RK, Kall K, Kilk K, Soomets U and Kahre T (2012) Prevalence of longchain 3-hydroxyacyl-CoA dehydrogenase deficiency in Estonia. JIMD Rep 2:79-85.

Kleijer WJ, Garritsen VH, van der Sterre MLT, Berning C, Häberle J and Huijmans JGM (2006) Prenatal diagnosis of citrullinemia and argininosuccinic aciduria: Evidence for a transmission ratio distortion in citrullinemia. Prenat Diagn 26(3):242-247.

Krous HF, Beckwith JB, Byard RW, Rognum TO, Bajanowski T, Corey T, Cutz E, Hanzlick R, Keens TG and Mitchell EA (2004) Sudden infant death syndrome and unclassified sudden infant deaths: A definitional and diagnostic approach. Pediatrics 114:234-238.

Laróvere LE, Ruiz SM, Angaroni CJ and de Kremer RD (2012) Molecular epidemiology of citrullinemia type I in a risk region of Argentina: A first step to preconception heterozygote detection. JIMD Rep 6:27-29.

Ledley FD, Lumetta MR, Zoghbi HY, VanTuinen P, Ledbetter SA and Ledbetter DH (1988) Mapping of human methylmalonyl CoA mutase (MUT) locus on chromosome 6. Am J Hum Genet 42:839-846.

Moura RR, Coelho AVC, Balbino VQ, Crovella S and Brandão LAC (2015) Meta-analysis of Brazilian genetic admixture and comparison with other Latin America countries. Am J Hum Biol 27:674-680.

Naslavsky MS, Yamamoto GL, de Almeida TF, Ezquina SAM, Sunaga DY, Pho N, Bozoklian D, Sandberg TOM, Brito LA, Lazar M et al. (2017) Exomic variants of an elderly cohort of Brazilians in the ABraOM database. Hum Mutat 38:751-763.
Nedoszytko B, Sieminska A, Strapagiel D, Dabrowski S, Slomka M, Sobalska-Kwapis M, Marciniak B, Wierzba J, Skokowski J, Fijalkowski M et al. (2017) High prevalence of carriers of variant c. $1528 \mathrm{G}>\mathrm{C}$ of HADHA gene causing long-chain 3hydroxyacyl-CoA dehydrogenase deficiency (LCHADD) in the population of adult Kashubians from North Poland. PLoS One 12:e187365.

Parra FC, Amado RC, Lambertucci JR, Rocha J, Antunes CM and Pena SD (2003) Color and genomic ancestry in Brazilians. Proc Natl Acad Sci U S A 100:177-182.

Pastinen T, Perola M, Ignatius J, Sabatti C, Tainola P, Levander M, Syvänen AC and Peltonen L (2001) Dissecting a population genome for targeted screening of disease mutations. Hum Mol Genet 10:2961-2972.

Piekutowska-Abramczuk D, Olsen RK, Wierzba J, Popowska E, Jurkiewicz D, Ciara E, Oltarzewski M, Gradowska W, Sykut-Cegielska J, Krajewska-Walasek M et al. (2010) A comprehensive HADHA c. $1528 \mathrm{G}>\mathrm{C}$ frequency study reveals high prevalence of long-chain 3-hydroxyacyl-CoA dehydrogenase deficiency in Poland. J Inherit Metab Dis 33:373-377.

Rashed MS, Bucknall MP, Little D, Awad A, Jacob M, Alamoudi M, Alwattar M and Ozand PT (1997) Screening blood spots for inborn errors of metabolism by electrospray tandem mass spectrometry with a microplate batch process and a computer algorithm for automated flagging of abnormal profiles. Clin Chem 43:1129-1141.

Shibata N, Hasegawa Y, Yamada K, Kobayashi H, Purevsuren J, Yang Y, Dung VC, Khanh NN, Verma IC, Bijarnia-Mahay S et al. (2018) Diversity in the incidence and spectrum of organic acidemias, fatty acid oxidation disorders, and amino acid disorders in Asian countries: Selective screening vs. expanded newborn screening. Mol Genet Metab Rep 16:5-10.

Summar ML, Koelker S, Freedenberg D, Le Mons C, Haberle J, Lee HS, Kirmse B, European Registry and Network for Intoxication Type Metabolic Diseases (E-IMD) and Members of the Urea Cycle Disorders Consortium (UCDC) (2013) The incidence of urea cycle disorders. Mol Genet Metab 110:179180.

Tyni T and Pihko H (1999) Long-chain 3-hydroxyacyl-CoA dehydrogenase deficiency. Acta Paediatr 88:237-45.

van Rijt WJ, Koolhaas GD, Bekhof J, Heiner Fokkema MR, de Koning TJ, Visser G, Schielen PC, van Spronsen FJ and Derks TG (2016) Inborn errors of metabolism that cause sudden infant death: A systematic review with implications for population neonatal screening programmes. Neonatology 109:297-302.

Zhu JM, Yang Z, Yu M, Wang R, Ye RH, Yang HX, Zhai GR and Wang Q (2005) Screening for the G1528C mutation in long chain fatty acid oxidation enzyme in Han nationality in Beijing population. Beijing Da Xue Xue Bao Yi Xue Ban 37:72-74.

Associate Editor: Regina C. Mingroni-Netto

License information: This is an open-access article distributed under the terms of the Creative Commons Attribution License (type CC-BY), which permits unrestricted use, distribution and reproduction in any medium, provided the original article is properly cited. 